IZA DP No. 8451

Money Can't Buy Love But Can It Buy Peace?

Evidence from the EU Programme for Peace and Reconciliation

Tilman Brück

Neil T. N. Ferguson

August 2014 


\title{
Money Can't Buy Love But Can It Buy Peace? Evidence from the EU Programme for Peace and Reconciliation
}

Tilman Brück

SIPRI and IZA

\author{
Neil T. N. Ferguson \\ SIPRI
}

\author{
Discussion Paper No. 8451 \\ August 2014
}

\author{
IZA \\ P.O. Box 7240 \\ 53072 Bonn \\ Germany \\ Phone: +49-228-3894-0 \\ Fax: +49-228-3894-180 \\ E-mail: iza@iza.org
}

Any opinions expressed here are those of the author(s) and not those of IZA. Research published in this series may include views on policy, but the institute itself takes no institutional policy positions. The IZA research network is committed to the IZA Guiding Principles of Research Integrity.

The Institute for the Study of Labor (IZA) in Bonn is a local and virtual international research center and a place of communication between science, politics and business. IZA is an independent nonprofit organization supported by Deutsche Post Foundation. The center is associated with the University of Bonn and offers a stimulating research environment through its international network, workshops and conferences, data service, project support, research visits and doctoral program. IZA engages in (i) original and internationally competitive research in all fields of labor economics, (ii) development of policy concepts, and (iii) dissemination of research results and concepts to the interested public.

IZA Discussion Papers often represent preliminary work and are circulated to encourage discussion. Citation of such a paper should account for its provisional character. A revised version may be available directly from the author. 


\section{ABSTRACT \\ Money Can't Buy Love But Can It Buy Peace? Evidence from the EU Programme for Peace and Reconciliation}

In 1998, the Good Friday Agreement concluded a period of violence in Northern Ireland yet the scars of the conflict remained prevalent in the political landscape. Rival communities remained divided, economic performance was poor and intercommunity tensions frequently manifested. In a bid to reinforce progress towards a peaceful and stable society, over $€ 1$ bn of public money was spent between 2000 and 2006 on small-scale community and business ventures. Despite the scale of expenditure, however, little rigorous effort has been made to test the success of the programmes. Splitting Northern Ireland into 582 electoral wards, we merge individual-level on perceptions of neighbourhood quality from the British Household Panel Survey with detailed PEACE II accounts. Noting potential selection and omitted variables biases, we implement two-stage random effects models and show that neither level of spending, nor number of projects, in a region is associated with improvements in perceptions of neighbourhood quality.

JEL Classification: D74, F35, H56, I38, O18

Keywords: aid intervention, peacebuilding, terrorism, political violence, Northern Ireland, PEACE II, EU Structural Fund, The Troubles

Corresponding author:

Neil T. N. Ferguson

Stockholm International Peace Research Institute (SIPRI)

Signalistgatan 9

SE-169 70 Solna

Sweden

E-mail: ferguson@sipri.org 


\section{Introduction:}

The signing of the Belfast Agreement on Good Friday 1998 is widely seen as the final act in the long process to bring peace to Northern Ireland. Despite the end of violence, however, the ethno-nationalist divisions that, in part, caused the outbreak of violence (Darby, 1995) remained prominent. Protestant and Catholic children, for example, were educated separately and a snake of "peace walls" physically divided the two communities in Belfast and other urban centres. Notwithstanding these issues, the period immediately following the signing of the Agreement remained one of hope and attention quickly turned to building a sustainable peace and future prosperity for Northern Ireland. In addition to the Track I political talks, therefore, a funding stream for so-called Track III diplomacy was developed; the European Union Programme for Peace and Reconciliation in Northern Ireland and the Border Region of Ireland 2000-2006 - more succinctly known as PEACE II. Funding was, predominantly, given to small-scale community led projects expected to have localised impacts, with a stated aim of, "[encouraging] progress towards a peaceful, stable society and [to] promote reconciliation." To this end, over €1bn was spent, amounting to almost $€ 500$ per capita in Northern Ireland and the six border counties - a sum more than double the UN's peacebuilding budget for the same period. ${ }^{1}$

Despite the extent of this spend and the number of projects funded, however, little meaningful effort has been made to evaluate the success of the programme. To date, no research has linked spending to the perceptions of individuals living in the treated regions, for example. Thus, it remains unclear if the spending of $€ 1 b n$ of taxpayer money had the desired effect of building peace and improving the economy of Northern Ireland. This article tackles these issues by asking the underlying research question about whether or not the PEACE II programme had a demonstrable impact on the perceptions of those living in treated regions. In doing so, we provide the first rigorous quantitative evidence on the effectiveness of the programme. By extension, we ask a second and nobler question about the possibility of building lasting peace and improving cross-community social interactions through financial expenditures. To answer these questions, we employ data on individuals' perceptions of the quality of their neighbourhoods. We source this data from the British Household Panel Survey and match them to PEACE II spending at ward level in Northern Ireland.

Noting potential biases, due to the non-random nature of the expenditure ${ }^{2}$ and individual and neighbourhood unobservables, we employ a series of random effects (RE) and instrumental variables (RE2SLS) approaches. Our initial RE specification suggests a positive and significant association between latent perceptions of neighbourhood quality and PEACE II spending. Using the

\footnotetext{
${ }^{1}$ See: http://www.unpbf.org/donors/key-figures/

${ }^{2}$ Rather than being randomly assigned across Northern Ireland and the border counties, PEACE II funded projects on quality and expected impact, which were assessed against a set of objective criteria. It is, therefore, highly likely that there are significant differences between the regions that received the treatment and those that did not.
} 
geographic variation of historical violence in Northern Ireland as a valid instrument, however, we show that once biases are accounted for this effect disappears. These findings suggest that, rather than having the desired impact of improving an array of neighbourhood indicators, PEACE II spending only reached areas where such indicators were already elevated. This calls into question both the success of the programme and the "open competition" model by which funding decisions were taken. The unconditional correlation between spending and neighbourhood deprivation, for example, is only $16 \%$. In contrast to this, recent evidence (Ferguson and Michaelsen, 2013) has shown that the most deprived neighbourhoods in Northern Ireland are those that suffered the highest violence in the past. It is not unlikely that these same neighbourhoods are those that would have benefitted most from receipt to PEACE II funds, yet our findings show that this was not the case.

The rest of this article is structured as follows; in Section 2, we provide a brief history of the conflict in Northern Ireland and information on PEACE II spending. We follow this with a literature review in Section 3. We discuss data and methodology in Sections 4 and 5 and finally, present our results and conclusions in Sections 6 and 7.

\section{Northern Ireland, the Border Counties, the Troubles and PEACE II:}

In July 1969 a Catholic civilian, Francis McCloskey, was killed during street disturbances in Dungiven, County Derry. Sutton (1994) suggests that the death of Mr McCloskey was the first fatality that directly pertained to the conflict in Northern Ireland. This death would herald an era of low-intensity, paramilitary, violence that would last for almost 30 years and would claim the lives of in excess of 3,500 individuals. With over $50 \%$ of the victims civilian, the conflict pitted British securities and two rival sets of paramilitaries, Loyalists and Republicans, against each other in two parallel conflicts (Ferguson, 2012). Although significant discussion surrounds the causes of the outbreak of conflict and the intensity of violence thereafter, two major triggers frequently arise in the literature. The likes of Darby $(1995,2003)$ links the onset of violence to centuries old ethno-nationalist tensions between the Protestant and Catholic communities. These tensions can be traced as far back as the Plantation of Ulster, which began in 1609 and saw British Protestant landowners implanted in the province. Economic causes are also commonly espoused, however. Fitzduff and O'Hagan (2009), for example, link the onset of violence to real and perceived inequalities between the communities while Honaker (2010) links the intensity of violence to changes in individual opportunity over time.

In 1994, violence in Northern Ireland officially ended when ceasefires were called by nearly all of the main militant organisations. These ceasefires laid the foundations for the multiparty political talks that, eventually, led to the signing of the Belfast Agreement in 1998. Despite the cessation of open conflict, however, both the ethno-nationalist divisions and reduced economic opportunity that precipitated the Troubles remained. Northern Ireland's economy lagged behind that of mainland Great Britain, for example and inter-community tensions remained easily visible. Education and neighbourhood demographics were 
broadly divided along religious lines, whilst communities in urban areas were often physically separated by so-called "peace walls". Even support for the Agreement itself was divided along ethnic lines with 95\% of Catholics but only $55 \%$ of Protestants voting in favour of ratification (ARK Northern Ireland).

In order to overcome these endemic divisions and the expectation that they could act as a barrier to long-term peace, a series of EU programmes were developed. Designed to augment the Track I political process by encouraging community participation in Track III diplomacy, they have seen in excess of $€ 2 b n$ spent in Northern Ireland and the border counties. While political progress at the time was apparent, with the Democratic Unionist Party the only mainstream group to oppose the peace process, improvements at the grassroots level were more stilted. The focus of these programmes was to stimulate reconciliation and progress at this level, in order to reinforce the high-level political progress. In the case of PEACE II, this focus translated itself into an attempt to directly involve individuals and communities in the transformation of Northern Ireland from a conflict-affected state into an "outward and forward looking region".

PEACE II, therefore, saw the development of an open competition model that invited bids for funding for projects that would develop "vertical and horizontal capacity" in all social strata (Buchanan, 2008). These projects would aim to have impacts at the highest levels of geographic disaggregation. The open competition drew some 12,000 applications, of which approximately half were funded. Some 4,000 of these projects were delivered in Northern Ireland, of which $90 \%$ were expected to have impacts that did not extend beyond the boundaries of a single electoral ward. Given the historical context of the causes of conflict, a vast majority of the funded projects were designed to lead to improvements in one of two general areas. The first grouping of funded projects were designed to improve the local and general economic performance of Northern Ireland, reducing inequality and increasing opportunity. The second aimed to address the underlying societal divisions that were present before the conflict and which were part of its legacy. To this end, five specific priorities were developed:

- Realising the economic opportunities developed by the peace process

- Social integration, inclusion and reconciliation, with priority given to vulnerable groups in the areas worse affected by the conflict, interface areas and areas where community infrastructure is weak

- Locally-based regeneration and development strategies

- Promoting an outward and forward-looking region by encouraging dialogue with other EU regions on economic, social and environmental issues;

- Economic, social and cultural cross-border cooperation.

In order to evaluate these programmes and to oversee their implementation, the Programme Monitoring Committee (PMC) was established and met regularly to discuss progress and performance. Specific details of these evaluations, however, are difficult to establish. Indeed, despite the whole operation of PEACE II, from the first successful application to the completion of the final programme, occurring over an entire decade, specific and open academic focus, particularly 
that concentrating on the success or impacts of the programme, is noticeably lacking. This article is the first to fill this alarming knowledge gap by conducting an ex post impact evaluation of the PEACE II programme.

\section{Literature:}

Traditional impact evaluation studies, particularly those focusing on the effectiveness of peacebuilding programmes, tend to follow rather specific experimental techniques. Typically, these approaches randomise a standard treatment, such that on average there should be no other observable differences between the receivers and the rest of the population. In such cases, therefore, studying the outcomes of those who received the treatment compared to those who did not can causally measure the impact of the intervention. A fuller discussion of these methodologies can be found in, for example, Gaarder and Annan (2013). Following such approaches, the success of peacebuilding programmes is often established in the literature. Such results, however, are most commonly based on observed improvements in easily measurable and objective outcome variables, such as education enrolment, labour force participation or income. Blattman and Annan (2011), for example, study the reintegration of ex-militants in Liberia and show significantly improved outcomes for those who received the treatment relative to those who did not. Gilligan et al. (2013) show similar effects for ex-combatants in Burundi, with participants showing significantly lower incidences of poverty.

Comparatively fewer programmes have sought to measure changes in individual perceptions as a result of peacebuilding programmes, however. In most cases such changes may be the overarching aim of the intervention and, therefore, studying them remains highly desirable. Improved perceptions of out-groups, for example, is likely to result in higher cross-community cohesion, which is a fundamental building block for stable and sustained peace. Fearon et al. (2008) suggest two main reasons for the absence of such information, however. First, if programmes are implemented in communities with greater or weaker cohesion than average, then comparison of outcomes will lead to inaccurate estimates of the programme's effects. Second, individual perceptions and patterns of social cooperation are difficult to measure, particularly in comparison to the more objective measures discussed in the previous paragraph. Fearon et al. (2008) overcome these complexities by randomising a treatment and adopting behavioural game theory techniques. In doing so, they show a positive impact of a community-driven reconstruction programme in the Democratic Republic of the Congo. This work shows increased community cohesion as a result of the programme but only weak evidence of improvements in material wellbeing. Similarly, Malhotra and Liyanage (2005) show positive effects on empathy towards out-groups due to attendance at peace-workshops in Sri Lanka.

Despite the massive extent of PEACE II expenditure, as noted in Buchanan (2008) alarmingly little work has set about evaluating the impact of the programme in the ways discussed above. Indeed, beyond a few mentions in passing (e.g. Arthur, 2000; Tannam, 2006, 2007; Hayward, 2007a, 2007b; O'Dowd and McCall, 2007), PEACE II appears to be almost entirely absent from 
academic discourse. To our knowledge, only two works, The Northern Ireland Attitudinal Survey (NIAS, 2005) and Byrne et al. (2009) touch on aspects of the effectiveness of PEACE II. NIAS (2005) collected a one-shot dataset from individuals in Northern Ireland and the border countries in 2004. This survey collected data on individuals' responses to a series of questions regarding their attitudes towards members of different communities. It did not, however, link the perceptions of individuals to the locations in which the spending took place. Rather, it compared the responses of individuals who had voluntarily been involved in PEACE II projects with those of individuals who had not.

The results of NIAS (2005) report that those who were involved in programme projects are more positively disposed to members of other communities than those who were not. Despite NIAS' (2005) suggestions of success, however, its approach raises significant selection bias concerns. Individuals who volunteer to be involved in peacebuilding programmes are already likely to feel more positively disposed towards members of other communities, for example. Given such biases and the one-shot nature of the data collected, it is therefore impossible to attribute causality for such "improved" perceptions to PEACE II. In order to overcome these methodological flaws, Byrne et al. (2009) collected data from 98 interviews conducted with community leaders in Belfast, Derry and the border area. Respondents were questioned on their perceptions of changes in cross-community contact and typically reported positive impressions as a result of the presence of PEACE II projects. This work, however, only indirectly measures the impacts of the projects and, once more, fails to link perceptions of individuals to the locations in which spending took place. Thus, whilst the programme is reported to have achieved the stated goals in the literature to date, knowledge gaps remain. These gaps are particularly apparent in the failure of the literature to link individuals, and their perceptions, to spending in the regions in which they live, as is more typical of the impact evaluation literature.

To address this issue, we draw on observable data collected at disaggregated geographic levels in Northern Ireland and present a robust evaluation of the programmes. In doing so, this article constitutes the first attempt to analyse the effects of PEACE II in a rigorous quantitative manner.

\section{Data:}

The lack of an inbuilt quantitative evaluation strategy within PEACE II is both a major limiting feature of the programme design and a profound encumbrance to researchers. No metrics were specifically designed to measure the outcomes of the programme and little specific data has been collected. Similarly, programme funds were not randomly assigned across Northern Ireland and the border counties but, rather, were spent in a more strategic manner. Thus, our ex post impact evaluation lacks both the randomisation of treatment suggested as desirable in Gaarder and Annan (2013) and the ability to use specific data sources or experimental approaches as in Fearon et al. (2008). Instead, we must rely on less well-established techniques and the use of non-specific individuallevel data. We propose that elevated perceptions of latent neighbourhood quality act as a strong proxy for the expected improvements in both local social cohesion 
and local economic performance that PEACE II aimed to have. Given the lack of comparable geographic units and data sources across the Irish border, we choose to focus on Northern Ireland, where about two thirds of PEACE II projects were located and where over $70 \%$ of programme spending was allocated.

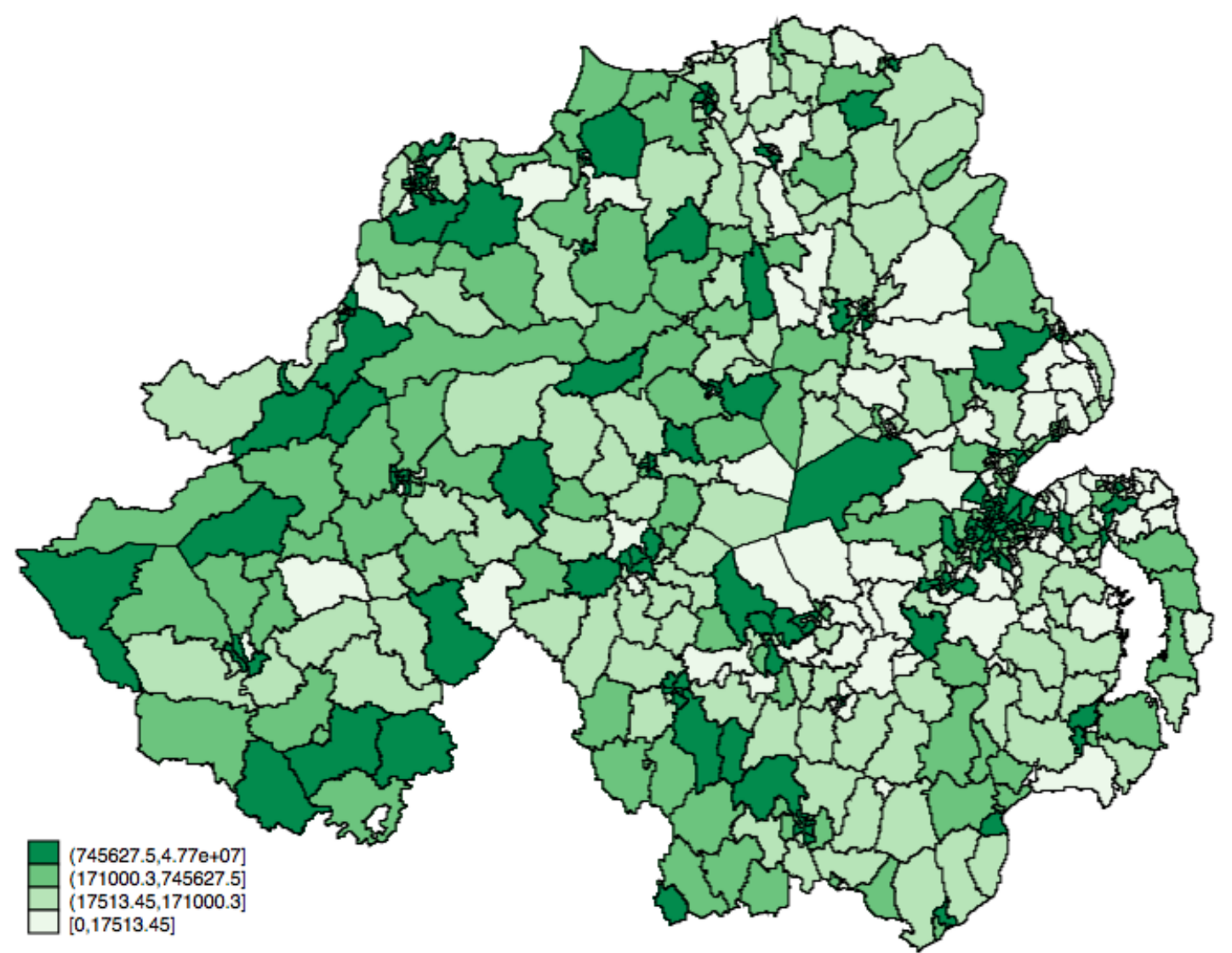

Figure 1: PEACE II spending by electoral ward. Source: Authors' construction of PEACE II monitoring committee data.

We source our data on perceptions of latent neighbourhood quality from the British Household Panel Survey (BHPS). The BHPS is an annual survey of individuals throughout the United Kingdom and has collected data in Northern Ireland since 2001. The survey is conducted with approximately 3,500 individuals in 2,000 households in Northern Ireland and is representative at this level. We use a subsample of the full data available from the BHPS that runs from 2001, which is the earliest available year of data until 2007, the year after PEACE II formally ended. This gives an unbalanced panel of $n \times T=11,664$ individualyears sourced from 523 of Northern Ireland's 582 electoral wards.

We focus on two questions of interest in the survey. The first asks individuals whether or not they like the neighbourhood in which they live. The second asks individuals about whether or not they would like to move house. We believe these questions to be the best source of data currently available for this analysis. First, given the failure of PEACE II to collect specific data, few alternatives are available. Secondly, given the various priorities of PEACE II spending and the dual approach of economic renewal and improvements in social cohesion, we require a measure that should be influenced by all strands of the programme. 
Measures of neighbourhood quality should increase equally with economic improvements as social improvements, suggesting the suitability of these measures for our purposes. Due to the incredibly low variation in responses to the first of these questions, we use the latter for our main analyses.

In doing so, we follow the residential mobility literature, which can be traced as far back as Speare (1974). Speare (1974) shows that residential satisfaction, including perceptions of latent neighbourhood quality, act as intervening variables in individuals' desire to move home. Furthermore, he suggests that once all other intervening variables are accounted for, the residual will measure individuals' perceptions of neighbourhood quality. Throughout the literature, a number of other intervening variables are mooted including; housing tenure and employment status (Böheim and Taylor, 2003), housing quality (Clark and Huang, 2004) and individual characteristics, including age, gender and education (Zaiceva and Zimmermann, 2008). By controlling for these individual and locational heterogeneities, we therefore transform individuals' desire to move home into a solid proxy of neighbourhood quality perceptions. We link these perceptions to the regional variation in PEACE II spending, shown in Figure 1. Should PEACE II have proven successful, the presence of either spending or projects in a location should then drive improvements in perceptions.

The BHPS also includes information on the other intervening variables of interest defined throughout the long residential mobility literature. In addition to our measure of neighbourhood quality, therefore, we garner all of the necessary individual-level information, including; age, gender, employment status, education, housing tenure type, whether or not an individual has moved house in the past year, etc. We also source information on the quality of the residence in which an individual lives and the quality of the area immediately surrounding a residence from this survey. ${ }^{3}$ We augment these measures with a measure of deprivation sourced from the Northern Ireland Statistical Research Agency (NISRA), which controls for the impacts of seven deprivation domains.

We geographically disaggregate this information to the electoral ward in which an individual lived at the time the survey interview was conducted. We match this data to a detailed database of all 12,000 applications for PEACE II funding.4 This database includes information on whether or not the application was successful, how much funding was given to each project and the location(s) in which the project was expected to have impacts. We restrict our interest to successful applications from Northern Ireland and to those that were expected have an impact within a single electoral ward. Our final dataset, therefore, includes approximately $85 \%$ of the projects that were funded in Northern

\footnotetext{
${ }^{3}$ We construct two indices that takes a value from $0-5$, where 5 is best and 0 worst. The first index is based on responses to a series of questions about the quality of a house, including type of windows, presence of leaks and so on. The second is based on responses to a series of questions regarding anti-social behaviour, light or noise pollution and so on.

${ }^{4}$ We are grateful to the Programme Monitoring Committee of the PEACE II programme for providing us with this data.
} 
Ireland. From this data, we derive two treatment variables; the first is the total expenditure by ward-year. The second is the number of funded projects by ward-year. We derive a contemporaneous measure of spending and a three-year lag of each. We generate this lag for three specific reasons. First, despite the project funding beginning in 2000, our first data observations were only collected in 2001. Inclusion of a lag, therefore, accounts for the left censored spending that would, otherwise, be excluded from our analysis. Second, the announcement of project funding may make little impact as and of itself. The creation of a longer-term lag therefore allows potential measurement of the impact of projects as they "come online". Finally, as suggested by the Special EU Programmes Body (SEUPB) of Northern Ireland, project impacts themselves may only occur in the longer-term. This lag accounts for each of these concerns.

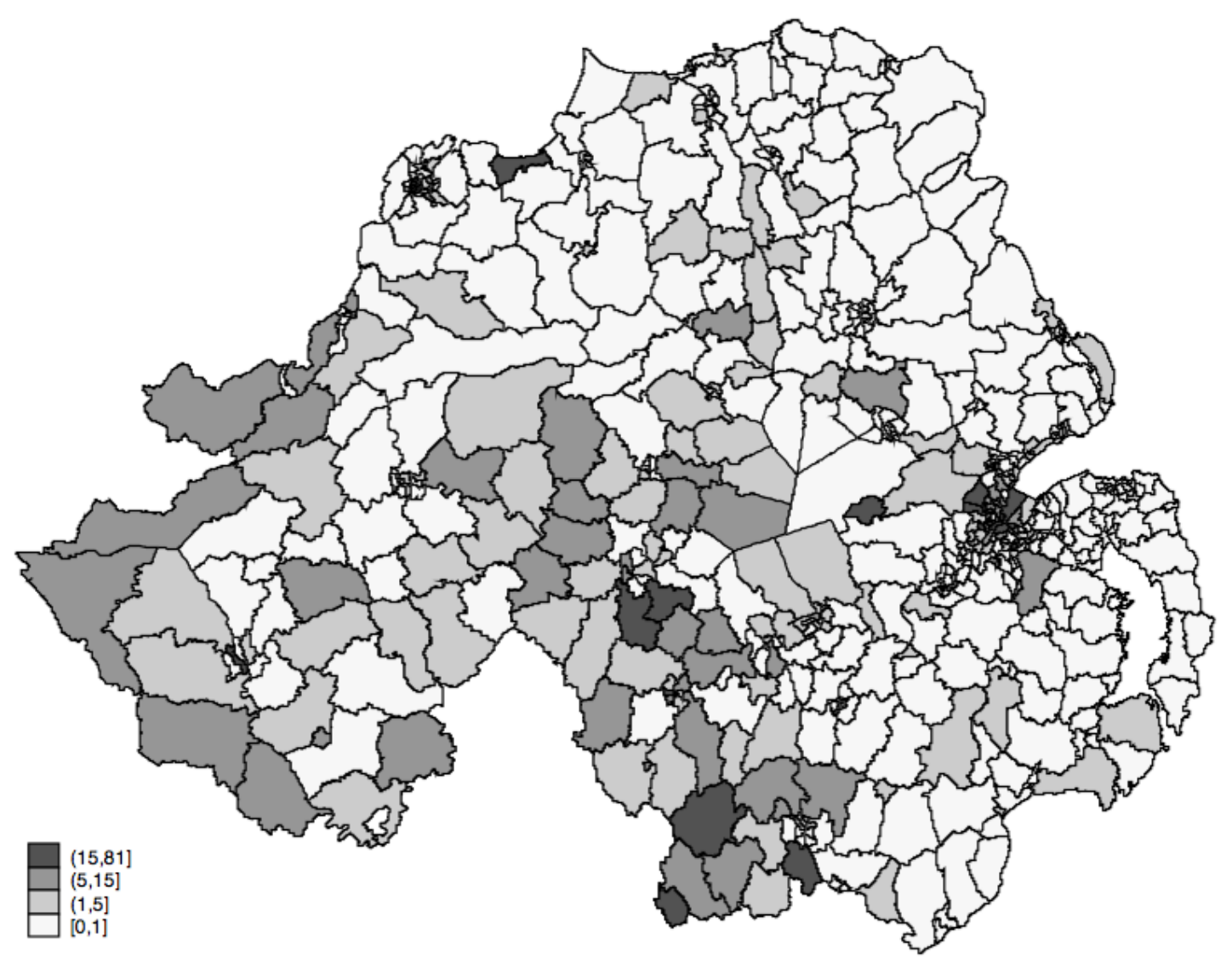

Figure 2: Spatial distribution of historical violence in Northern Ireland. Source: Authors' construction of Sutton (1994).

Due to the method in which funding decisions were taken, significant biases are likely to arise. In order to overcome these biases, we follow an instrumental variables approach, which we discuss fully in the next section. Our analysis shows the spatial distribution of historical violence in Northern Ireland to be a strong and valid instrument for the potentially endogenous treatment variables. We source this violence data from Malcolm Sutton's (1994) index of deaths from the conflict in Ireland, which we geographically disaggregate to Northern Ireland's electoral wards. From this data, we construct two instruments. The first is the variable deaths, which is the total number of fatalities that occurred in an 
electoral ward between the death of Francis McCloskey in 1969 and the Provisional IRA ceasefire in August 1994. As can be seen in Figure 2, there is significant spatial heterogeneity in the intensity of violence. Some 200 wards experienced no fatal violence during the conflict, whilst others experienced in excess of 75 deaths. The second variable we construct is the spatial lag of the deaths variable, which we create using a non-truncated inverse distance weighting matrix due to Northern Ireland's small geographic size.

\section{Methodology:}

The open competition model by which funding decisions were taken during the PEACE II programme suggests that it's impossible to believe that expenditure was randomly distributed throughout Northern Ireland. Whilst the selection criteria are relatively objective, the nature of the process suggests significant biases will arise should simple OLS models be followed. For example, should spending be specifically targeted in the lowest quality neighbourhoods in Northern Ireland, OLS models run the risk of falsely reporting a negative impact of PEACE II spending, as it is likely that individuals in these areas perceive their neighbourhoods to be of low quality. Alternatively, however, by asking individuals and groups to come together to submit an application, never mind a successful one, some minimum threshold of community cohesion may already be required. In such situations, neighbourhoods with lower social cohesion are less likely to receive funding than other areas. In this situation, OLS models run the risk of falsely reporting success of the projects, simply because spending more readily reaches neighbourhoods with already-elevated perceptions of quality. $A$ priori, we therefore remain agnostic on the direction of such potential biases.

To overcome these biases, we follow an instrumental variables approach as described in, for example, Angrist and Pishke (2009). This approach requires at least one "instrument" that is correlated with each treatment variable but that is uncorrelated with the regression error term. We employ two instruments from the pattern of historical violence during the Troubles, as described in the previous section. Due to the potential for collinarity between these instruments, we employ the third order polynomial of the spatial lag of violence in order to maximise variation between the two measures. In this way, we can write the basic relationship as a hierarchical model:

$$
S T A Y_{i j k t}=\beta_{1} \operatorname{TREAT}_{k t}+\beta_{2} X_{i t}+\beta_{3} Y_{j t}+\beta_{4} Z_{k t}+u_{i t}+v_{j t}+w_{k t}+\epsilon_{i j k t}
$$

where; $i$ is the subscript for the individual-level variables, $j$ for the house-level variables and $\mathrm{k}$ for the ward-level neighbourhood variables. STAY is a binary variable that determines whether or not an individual wishes to move house at time $t$, whilst TREAT is the endogenous measure of PEACE II spending / projects in location $\mathrm{k}$ at time $\mathrm{t}$. $\mathrm{X}, \mathrm{Y}$ and $\mathrm{Z}$ are vectors of exogenous regressors at individual, house and ward level. $u$ measures unobserved individual heterogeneity, $v$ unobserved house heterogeneity and $\mathrm{w}$ unobserved ward-level heterogeneity. Due to the potential for endogeneity bias, where the errors are unobserved but potentially correlated with TREAT, OLS estimates may be biased and inconsistent. In order to overcome the potential bias, we implement an 
instrumental variables approach by regressing the endogenous variable, TREAT on all exogenous regressors, $\mathrm{X}, \mathrm{Y}$ and $\mathrm{Z}$ and on the instruments, denoted IV.

$\operatorname{TREAT}_{k t}=\alpha_{0}+\alpha_{1} X_{i t}+\alpha_{2} Y_{j t}+\alpha_{3} Z_{k t}+\alpha_{4} I V_{k}+\eta_{k}$

where $\eta$ is the regression error term and $\alpha_{i}$ the regression coefficients.

In order for the instruments to be valid, $\alpha_{3}$ must be correlated with the endogenous variable, TREAT but not with the error term in the first stage regression. Put alternatively, $\alpha_{3} \neq 0$ and $\operatorname{COV}(I V, \epsilon)=0$. Whilst we show, statistically, that our instruments fulfill the first condition ${ }^{5}$, we can only argue the exclusion restriction qualitatively, as we present a just identified analysis, where the number of instruments equals the number of endogenous regressors.

First of all, given that violence ended 7 to 14 years before our analysis begins, there is no explicit reason to believe that it is a direct determinant of perceptions of current neighbourhood quality. Thus, impacts would need to be more indirect. It is possible, for example, that violence could have created persistent regional deprivation. Similarly, local services may be lacking due to fear of property or livelihood damage, for example. Other factors like high crime rates may be associated with historical violence as former combatants turn to other illegal activities for a livelihood. ${ }^{6}$ All of these phenomena are likely to link historical violence to current perceptions of neighbourhood quality. We control for all of these potential indirect effects using the Northern Ireland Multiple Deprivation Measure (NIMDM), however, precluding these sources of instrument invalidity. This measure includes information on seven domains of deprivation; income, employment, education, health, crime, access to services and living environment. Similar controls, such as current employment status, education, tenure type and so on preclude similar effects at individual or household levels. Thus, given the included controls and the use of violence that ended a significant period before our sample, we offer evidence that refutes conceivable sources of invalidity.

Although our treatment variables are time-varying, our instruments are not. Thus, whilst the use of fixed effects approaches might be desirous, we employ random effects approaches in order to account for individual heterogeneities. Given to the nature of our dependent variable, the direct implementation of binary dependent variable IV models may also be desirable but due to computational intensity we use more traditional panel techniques, which still provide unbiased coefficients (Angrist and Pischke, 2009, p. 198). We conduct two main variations of this analysis. The first follows a one-stage random effects approach, whilst the second implements the random effects two least squares model. We present the impact of total regional spending and total number of regional projects, by start year, as our baseline analysis. Given the number of specific measures funded within the programme which may not be expected to have noticeable impacts on perceptions of neighbourhood quality, such as

5 The Cragg-Donald F Statistic identifies that the instrument is strong, passing the Stock-Yogo threshold at 1\%.

6 See, e.g. McElrath et al. (2002). 
stimulation of Northern Ireland's farming economy, robustness checks, supporting our reported findings, are carried out using subsamples of spending. The first subsample focuses on all Priority 2 projects, ${ }^{7}$ whilst the second uses a list of projects from a list of specifically selected measures. ${ }^{8}$ Spending by end year is also employed. Our final robustness checks vary the form of the independent variables and instruments, with spending per capita and violence per capita used, as well as the use of a three-year lag of spending, rather than the sum total of prior spending.

\section{Results:}

The "first stage" of our results links spatial variation of PEACE II funding to historical regional violence. The results of these artificial first-stages are presented in Column 1 of Table 4 for the deaths instrument and Column 2 for the third order polynomial of the spatial lag of the deaths instrument (sldeaths). These results show that both instruments are strong predictors of total expenditure, lagged expenditure, total number of projects and lagged total of projects. Perhaps unsurprisingly, this historical intensity of conflict is shown to be a positive and accurate predictor of the locations in which PEACE II projects were funded. In addition to the high correlations depicted in Table 4, the CraggDonald F statistic identifies that the instruments are strong enough to identify a causal relationship in the second stage of the regression, passing the Stock-Yogo threshold at $1 \%$. The results of the main analyses are presented in Table 1 for total spending by region and Table 2 for the total number of projects by region.

In Columns 1-3 of Tables 1 and 2, we present the results of our one-stage random effects models with the inclusion of different sets of control variables at the individual, house and local area level. These one-stage analyses suggest a positive and significant impact on our proxy of neighbourhood quality due to contemporaneous PEACE II spending. The insignificant lag of spending suggests no longer-term effects, however. In other words, these results imply that individuals living in the areas that received the highest amounts of PEACE II investment each year have higher perceptions about the quality of their neighbourhood. This effect is more diluted when we look at number of projects, rather than spending. Heterogeneity, both of project types and in the level of financing received by each project, however, suggests this relationship will be noisier and the effects more difficult to ascertain. Despite this, however, the fully controlled one-stage analysis still suggests a significant and positive correlation.

We report the findings from our two-stage models in Columns 4-6 of Tables 1 and 2. In these analyses, where causality is identified using instrumental variables techniques, we see two important changes to the reported effects. The sign of the coefficient changes from positive to negative in these analyses and,

\footnotetext{
${ }^{7}$ Priority 2 projects are those specifically implemented to promote community cohesion.

8 These measures were specifically chosen by the authors as those most likely to have specific impacts on perceptions of neighbourhood quality, as they are those specifically directed at improving community cohesion.
} 
more importantly, the outcomes become statistically insignificant. This move from a positive and significant correlation to an insignificant causal relationship confirms one of our hypothesised sources of bias. The open competition model for PEACE II funds appears to have given rise to a situation where individuals in the communities that needed funds the most were also those least capable of submitting successful applications. Put alternatively, our one-stage and twostage models show that individuals in areas that received more funds exhibit higher perceptions of neighbourhood quality than others but that this relationship is not causal. Thus, spending appears to have reached only those communities that exhibited already-elevated perceptions of quality but it does not otherwise play a role in determining individuals' feelings about the neighbourhood in which they live. This assertion is further supported by the fact that our lagged intervening variables of interest are insignificant in all models. This suggests, not only that PEACE II did not necessarily reach the neighbourhoods most in need of support but also that it is not associated with any longer-term improvements in the areas in which projects were funded.

The strength of these findings is supported by the close fit between the results of our control variables and the hypotheses of the geographic mobility literature on which we draw (e.g. Speare, 1974). These findings show that both the significance and sign of these control variables matches the theoretical hypotheses of this literature ${ }^{9}$. Older individuals, for example, are more likely to wish to stay in their current location than younger ones. Similarly, individuals who own the property in which they live are more likely to wish to stay than those who do not. Property size, quality of the property and quality of the immediate surrounding area are also positive and significant drivers of desire to stay. Unsurprisingly, lack of space, population density and regional deprivation all decrease desire to stay. Finally, highly educated individuals are less likely to wish to stay, which fits with a long-line of education research (See: Greenwood, 1969). These findings suggest that our analysis has accurately picked up on the effects we would expect from the geographic mobility literature, supporting our notion, built on this literature, that once such factors are accounted for, desire to stay accurately proxies latent neighbourhood quality.

In the analyses where account for potential sources of bias, we show that there is no causal link between these perceptions of neighbourhood quality and the extent of PEACE II spending in that area. This stands in stark contrast to the theoretical expectations of a programme that expressly sought to improve local economic performance, social capital and cohesion. Whilst it is theoretically obvious why localised development in such phenomena should lead to improved perceptions of neighbourhood quality, these improvements are not realised. Given the nature of the bias we find and the open competition of PEACE II, however, we show that the main driving feature of these results is that funds did not reach the neighbourhoods most in need of them. This selection mechanism does not appear to have correctly identified the regions of Northern Ireland where peacebuilding and economic and community development were most needed. The unconditional correlation between indicators of need as simple as

9 These results are available on request from the corresponding author. 
regional deprivation, for example, is in the low range. In contrast to this, however, recent research (e.g. Ferguson and Michaelsen, 2013) shows that the most deprived areas in Northern Ireland now are also those that suffered the greatest levels of violence in the past. It is not unlikely that such areas are also expected to have been those in which PEACE II spending was most needed. In such a context, we do not suggest that the funded projects, themselves, were inherently flawed as peacebuilding devices but that there was a problematic disconnect between the criteria that judged the quality of these programmes and information on where they would have the most pronounced impacts.

\section{Conclusion:}

PEACE II was a six-year EU funded programme designed to build on the Track I political process to bring a long-term and sustainable peace to Northern Ireland. Over these six years, approximately $€ 1$ bn was spent on community-instigated projects with the aim of bringing those communities together and reconciling past differences. Despite the huge outlay, however, official monitoring of the programme's success is, at best, lacking in transparency. Similarly, discussion of the effectiveness of the programme, particularly in a quantitative manner, is almost entirely lacking in the literature. Hitherto, attempts to measure the effectiveness of the projects ex post (e.g. NIAS, 2005; Byrne et al., 2009) have entirely failed to directly measure the impact of the programmes on the perceptions of individuals living in the treated regions. This research bridges this gap but shows no significant positive impacts of the programmes when we control for potential sources of biases and other intervening variables.

A cursory glance at recent developments in Northern Ireland may suggest that such a finding is not entirely unexpected. Almost fifteen years after the programme began, inter-community tensions remain prevalent and, whilst improving, economic performance still lags behind mainland Britain. Schooling remains segregated along religious lines and the number of peace walls has actually increased since PEACE II began. Jarman (2012), for example, shows that more have been built since 1998 than were standing when the Good Friday Agreement was signed. Rioting between rival communities is not infrequent, while dissident Republican paramilitary organisations are a growing threat and have carried out a number of fatal and potentially fatal attacks in recent times.

Despite these relatively depressing findings and the pessimistic scenes coming from Northern Ireland, however, our results offer intuition for how the effectiveness of peacebuilding programmes can be improved in the future. More careful consideration must be given, not just to the quality of the projects funded as in PEACE II, but also to the locations that will benefit most from peacebuilding investment. Such identification is not easy. Following the intuition of Fearon et al. (2008), for example, significant complexities arise in measuring phenomena such as community cohesion. By extension, these difficulties are suggestive of the arduous task of identifying where peacebuilding may be required the most. At the same time, success of such interventions could be significantly improved by more accurate methods of determining need. Future interventions, therefore, require a series of metrics that can facilitate this more accurate targeting. 
In the case of PEACE II, however, our results show that spending did not even reach the areas with the worst observable social issues, such as deprivation. The impact of such a failure is deeply troubling. PEACE II was designed to target areas with the weakest social and community infrastructure. At the same time, successful receipt of funding required communities to come together to submit applications that were judged against a set of objective criteria. It seems likely that areas with the weakest community infrastructure are also the areas least likely to successfully come together in such a way. This direct contraction between the aims of the programme and the administration of funding should offer a stark warning to future peacebuilding programmes. It is almost certain that the open competition method followed prevented funds from reaching the communities they were designed to help, inhibiting success of the programme.

Therefore, whilst the targeted spending of peacebuilding interventions is unlikely to be an inherently bad thing, the outcomes of PEACE II suggest that how spending is targeted must be more carefully considered. The success of targeted spending requires policymakers to accurately determine the areas that will benefit most from intervention, as well as evaluating the quality of the interventions. While accurately determining these areas in an objective manner remains complex, the outcomes of PEACE II suggest that certain methods of administration are more likely to reduce the probability of success. By avoiding methods that could encumber participation by the individuals and communities most in need, success of future programmes will be made more likely. 


\section{References:}

Angrist, J. and J. Pischke (2008). Mostly Harmless Econometrics: An Empiricist's Companion. Princeton University Press, Princeton

ARK Northern Ireland (2001). "The 1998 Referendums." Available online: http://www.ark.ac.uk/elections/fref98.htm

Arthur, P. (2000): "Special Relationships: Britain, Ireland and the Northern Ireland Problem." Blackstaff Press, Belfast

Blattman, C. and J. Annan (2011): "Reintegrating and Employing High-Risk Youth in Liberia: Lessons from a Randomised Evaluation of a Landmine Action Agricultural Training Programme." Povery Action Document Available Online: http://www.poverty-action.org/sites/default/files/blattman_annan_excom_reintegration_ipa_liberia_1.pdf

Böheim, R and M. Taylor (2003): "Tied Down or Room to Move? Investigating the Relationships Between Housing Tenure, Employment Status and Residential Mobility in Britain." Scottish Journal of Political Economy 49(4): 369-392

Buchanan, S. (2008): "Transforming Conflict in Northern Ireland and the Border Counties: Some Lessons from the Peace Programmes on Participative Democracy." Irish Political Studies 23(3): 387-409

Byrne, S., J. Arnold, E. Fissuh, K. Standish, C. Irvine and P. Tennent (2009): "The EU PEACE II Fund and the International Fund for Ireland: Nurturing CrossCommunity Contact and Reconciliation in Northern Ireland." Geopolitics 14(4): 630-652

Clark, W. and Y. Huang (2004): "Linking Migration and Mobility: Individual and Contextual Effects in Housing Markets in the UK." Regional Studies 38(6): 617628

Darby, J. (1995): “Conflict in Northern Ireland: A Background Essay.” In S. Dunn (Ed) Facets of the Conflict in Northern Ireland. Macmillan Press, London

Darby, J. (2003): "Northern Ireland: The Background to the Peace Process." CAIN: http://cain.ulst.ac.uk/events/peace/darby03.htm

Fearon, J., M. Humphreys and J. Weinstein (2008): "Can Development Aid Contribute to Social Cohesion after Civil War? Evidence from a Field Experiment in Post-Conflict Liberia." American Economic Review: Papers and Proceedings 99(2): 287-291

Ferguson, N. and M. Michaelsen (2013): "The Legacy of Conflict: Regional Deprivation and School Performance in Northern Ireland." IZA Discussion Paper No. 7489, July 2013 
Ferguson, N. (2012): "A Duration Analysis of Terrorist Strategy in Domestic Conflict: Evidence from Northern Ireland, 1971 - 1994” Economics of Security Working Paper 68, Berlin

Fitzduff, M. and L. O'Hagan (2009): “The Northern Ireland Troubles.” INCORE Background Paper. CAIN: http://cain.ulst.ac.uk/othelem/incorepaper.htm

Gaarder, M. and J. Annan (2013): "Impact Evaluation of Conflict Prevention and Peacebuilding Interventions." Policy Research Working Paper No. 6496. World Bank, Washington DC.

Gilligan, M., E Mvukiyehe and C. Samii (2013): "Reintegrating Ex-Rebels into Civilian Life: Quasi-Experimental Evidence from Burundi." Journal of Conflict Resolution 57(4): 598-626

Greenwood, M. (1969): "An Analysis of the Determinants of Geographic Labour Mobility in the United States." The Review of Economics and Statistics 51(2): 189-194

Hayward, K. (2007a): "Building on the EU's Legacy: Cross-Border Cooperation in Ireland." Administration 55(3): 51-74

Hayward, K. (2007b): "Mediating the European Ideal: Cross-Border Programmes and Conflict Resolution on the Island of Ireland." Journal of Common Market Studies 45(3): 675-693

Honaker, J. (2010): “Unemployment and Violence in Northern Ireland: A Missing Data Model for Ecological Inference.” Working Paper

Malhotra, D. and S. Liyange (2005): "Long-Term Effects of Peace Workshops in Protracted Conflicts." Journal of Conflict Resolution 49(6): 908-924

NISRA (2005): "Attitudinal Survey: A NISRA Report for the Distinctiveness Working Group, PEACE II Monitoring Committee." Available online: http://www.seupb.eu/Libraries/PEACE_Programme_Evaluations/Attitudinal.sfl b.ashx

O'Dowd, L. and C. McCall (2007): "The Voluntary Sector: Promoting Peace and Cooperation." In J. Coakley and L. O'Dowd (Eds) Crossing the Border: New Relationships Between Northern Ireland and the Republic of Ireland. Irish Academic Press, Dublin

Speare, A. (1974): "Residential Satisfaction as an Intervening Variable in Residential Mobility." Demography 11(2): 173-188

Sutton, M. (1994): "Bear in Mind these Dead: An Index of Deaths from the Conflict in Ireland." Beyond the Pale Publications, Belfast 
Tannam, E. (2006): "Cross Border Cooperation Between Northern Ireland and the Republic of Ireland: Neo-Functionalism Revisited." The British Journal of Politics and International Relations 8(2): 256-276

Tannam, E. (2007): "Public Policy: The EU and the Good Friday Agreement." In J. Coakley and L. O'Dowd (Eds) Crossing the Border: New Relationships Between Northern Ireland and the Republic of Ireland. Irish Academic Press, Dublin

Zaiceva, A and K. Zimmermann (2009): "Scale, Diversity and Determinants of Labour Migration in Europe." Oxford Review of Economic Policy 24(3): 428-452 
Table 1: Effect of Total Expenditure

$\begin{array}{lllccc}(1) & (2) & (3) & (4) & (5) & (6) \\ R E & R E & R E & \text { RE2SLS } & \text { RE2SLS } & \text { RE2SLS }\end{array}$

VARIABLES CONTROLS

\begin{tabular}{|c|c|c|c|c|c|c|c|}
\hline \multirow[t]{2}{*}{ total spend } & & $9.76 \mathrm{E}-09 * *$ & $1.07 \mathrm{E}-08^{* *}$ & $1.19 \mathrm{E}-08 * * *$ & $-1.54 \mathrm{E}-07$ & $-8.31 E-08$ & $-2.97 \mathrm{E}-07$ \\
\hline & & $(4.42 \mathrm{E}-09)$ & (4.39E-09) & (4.43E-09) & (1.91E-07) & (1.87E-07) & (3.25E-07) \\
\hline \multirow[t]{5}{*}{ lagged spend } & & $-2.64 \mathrm{E}-09$ & $-1.79 \mathrm{E}-09$ & $-1.04 \mathrm{E}-09$ & $2.93 \mathrm{E}-08$ & $1.66 \mathrm{E}-08$ & $1.02 \mathrm{E}-07$ \\
\hline & & $(2.35 \mathrm{E}-09)$ & $(2.32 \mathrm{E}-09)$ & (2.39E-09) & (7.25E-08) & (7.01E-08) & (1.17E-07) \\
\hline & Individual & YES & YES & YES & YES & YES & YES \\
\hline & House \& Environ & NO & YES & YES & NO & YES & YES \\
\hline & Regional & NO & NO & YES & NO & NO & YES \\
\hline Individuals & & 1704 & 1704 & 1704 & 1704 & 1704 & 1704 \\
\hline Observations & & 11664 & 11664 & 11664 & 11664 & 11664 & 11664 \\
\hline
\end{tabular}

Standard errors in parenthesis

${ }^{* * *} p<0.01,{ }^{* *} p<0.05,{ }^{*} p<0.1$ 
Table 2: Effect of Total Number of Projects

\begin{tabular}{|c|c|c|c|c|c|c|c|}
\hline & & (1) & (2) & (3) & (4) & (5) & (6) \\
\hline & & RE & RE & $\mathrm{RE}$ & RE2SLS & RE2SLS & RE2SLS \\
\hline VARIABLES & CONTROLS & & & & & & \\
\hline \multirow[t]{2}{*}{ total projects } & & $1.61 \mathrm{E}-03$ & $2.38 \mathrm{E}-03$ & $3.16 \mathrm{E}-03 *$ & -0.088 & -0.049 & -0.165 \\
\hline & & (1.65E-03) & (1.63E-03) & $(1.6 \mathrm{E}-03)$ & $(0.078)$ & $(0.074)$ & $(0.214)$ \\
\hline \multirow[t]{5}{*}{ lagged projects } & & $-1.29 \mathrm{E}-03$ & $-6.52 E-04$ & $-2.83 E-05$ & 0.026 & 0.015 & 0.062 \\
\hline & & (8.59E-04) & (8.47E-04) & (8.92E-04) & $(0.032)$ & (0.029) & $(0.082)$ \\
\hline & Individual & YES & YES & YES & YES & YES & YES \\
\hline & House \& Environ & NO & YES & YES & NO & YES & YES \\
\hline & Regional & NO & NO & YES & NO & NO & YES \\
\hline Individuals & & 1704 & 1704 & 1704 & 1704 & 1704 & 1704 \\
\hline Observations & & 11664 & 11664 & 11664 & 11664 & 11664 & 11664 \\
\hline
\end{tabular}

Standard errors in parenthesis

${ }^{* * *} p<0.01,{ }^{* *} p<0.05,{ }^{*} p<0.1$ 


\section{Appendix A}

Table 3: One-Stage Analysis with Instruments Included as Independent Variables

\begin{tabular}{|c|c|c|c|}
\hline VARIABLES & CONTROLS & $\begin{array}{l}\text { (1) } \\
\mathrm{RE}\end{array}$ & $\begin{array}{l}\text { (2) } \\
R E\end{array}$ \\
\hline total spend & & $\begin{array}{l}1.22 \mathrm{E}-08 * * * \\
(4.48 \mathrm{e}-09)\end{array}$ & \\
\hline lagged spend & & $\begin{array}{l}-8.21 \mathrm{E}-10 \\
(2.46 \mathrm{E}-09)\end{array}$ & \\
\hline total projects & & & $\begin{array}{l}0.0032^{*} \\
(0.0017)\end{array}$ \\
\hline lagged projects & & & $\begin{array}{l}(1.69 E-05) \\
(9.2 E-04)\end{array}$ \\
\hline deaths & & $\begin{array}{l}5.5 \mathrm{E}-04 \\
(9.1 \mathrm{E}-04)\end{array}$ & $\begin{array}{l}5.5 E-04 \\
(9.1 E-04)\end{array}$ \\
\hline sldeaths & & $\begin{array}{l}-2.4962 \\
(2.2044)\end{array}$ & $\begin{array}{l}-2.3097 \\
(2.1930)\end{array}$ \\
\hline & $\begin{array}{l}\text { individual } \\
\text { house \& environ } \\
\text { regonal }\end{array}$ & $\begin{array}{l}\text { YES } \\
\text { YES } \\
\text { YES }\end{array}$ & $\begin{array}{l}\text { YES } \\
\text { YES } \\
\text { YES }\end{array}$ \\
\hline $\begin{array}{l}\text { Individuals } \\
\text { Observations }\end{array}$ & & $\begin{array}{l}1704 \\
11664\end{array}$ & $\begin{array}{l}1704 \\
11664\end{array}$ \\
\hline
\end{tabular}

Standard errors in parenthesis $* * * p<0.01, * * p<0.05, * p<0.1$ 
Appendix B

Table 4: RE2SLS First Stage Outputs

\begin{tabular}{|c|c|c|c|}
\hline VARIABLES & INSTRUMENT & $\begin{array}{c}(1) \\
\text { deaths }\end{array}$ & $\begin{array}{c}\text { (2) } \\
\text { sldeaths }\end{array}$ \\
\hline total spend & & $\begin{array}{l}19338.56 * * * \\
(1647.313)\end{array}$ & $\begin{array}{l}5.41 \mathrm{E}+07 * * * \\
(3935742)\end{array}$ \\
\hline lagged spend & & $\begin{array}{l}60298.52 * * * \\
(3083.917)\end{array}$ & $\begin{array}{l}1.35 \mathrm{E}+08^{* * *} \\
(7368061)\end{array}$ \\
\hline total projects & & $\begin{array}{l}0.0581463^{* * *} \\
(0.0044397)\end{array}$ & $\begin{array}{l}123.1751^{* * *} \\
(10.62682)\end{array}$ \\
\hline lagged projcts & & $\begin{array}{l}0.1628925^{* * *} \\
(.0083591)\end{array}$ & $\begin{array}{l}293.7243 * * * \\
(20.00838)\end{array}$ \\
\hline $\begin{array}{l}\text { Individuals } \\
\text { Observations }\end{array}$ & & $\begin{array}{l}1704 \\
11664\end{array}$ & $\begin{array}{l}1704 \\
11664\end{array}$ \\
\hline
\end{tabular}

Standard errors in parenthesis

$* * * p<0.01, * * p<0.05, * p<0.1$ 